\title{
X-ray fluorescence analysis using synchrotron radiation: principles, methods and applications in several scientific fields of natural sciences
}

\section{Carlos A. Pérez}

\author{
X-Ray Fluorescence (XRF) Group - Laboratório Nacional de Luz Síncrotron (LNLS) \\ Centro Nacional de Pesquisas em Energias e Materiais (CNPEM) \\ Caixa Postal 6192, Campinas-SP, Brazil. \\ E-mail: carlos.perez@lnls.br
}

\begin{abstract}
Among the large variety of analyzing methods for the quantitative determination of trace elements, multielement methods are of special interest. X-Ray Fluorescence (XRF) analysis is well suited for this purpose. The XRF method can enter in the field of trace element analysis if some modifications of the classic XRF are introduced, mainly related to the primary excitation, i.e., the use of monochromatic radiation, excitation mass reduction by using $\mathrm{x}$-ray microbeams or grazing-incident/exit excitation conditions and polarized radiation. Synchrotron radiation sources meet very well the above requirements thus making the XRF analysis with synchrotron radiation (SR-XRF) the most sensitive multi-element method for bulk analysis in small amount of sample.

The scope of this short course consists of introducing the theoretical principles of quantitative analysis in $\mathrm{X}$-ray fluorescence spectrometry, focusing in energy dispersive system (ED-XRF). Variants of the conventional technique that are highly improved using synchrotron radiation, such as micro-XRF imaging (2D/3D), micro-X-ray absorption spectroscopy (specifically micro-XANES) and total reflection XRF (TXRF), will be also described. Selected applications will be given to illustrate these techniques. Looking to the future of the analytical capability of the SR-XRF analysis, some features of the Coherence X-Ray Nanofocus (CARNAUBA) beamline, to be installed at the new $4^{\text {th }}$ generation machine SIRIUS, will be sketched.
\end{abstract}

